\title{
Instantaneous Plastic Flow Properties of Thin Brass Sheets Under Uniaxial and Biaxial Testing
}

Feliks Stachowicz(PL) stafel@prz.edu.pl

\section{BIOGRAPHICAL NOTES}

Feliks Stachowicz, prof. DSc, PhD, Eng. (born in 1951) graduate of the Faculty of NonFerrous Metals at AGH University of Science and Technology in Kraków (1975), he specializes in evaluating metals usability for cold forming processes (especially forming limits of thin sheet metal) and analyses of basic parameters concerning technological forming processes of sheet metal, pipes and structural profiles as ell as recycling processes. In 1981 he defended PhD degree, in 1991 obtained DSc degree and in 2000 he was awarded the professor's degree. Member of the Section of Plastic Forming Processes Theory in Committee on Metallurgy at Polish Academy of Science. In years 1999-2002 and 2005-2008 dean of Faculty of Mechanical Engineering and Aeronautics, since 2008 vice rector for general affairs of Rzeszow University of Technology.

\section{KEY WORDS}

Plastic Anisotropy, Strain Hardening, Strain State, Forming Limit, Sheet Metal

\section{ABSTRACT}

In the prediction of formability of sheet metals, it is necessary to determine material properties which are normally evaluated on the data obtained by performing simple tests. The most important parameters affecting the value of limit strains of a sheet metal are the strain hardening exponent (n) and plastic anisotropy ratio (r). It was established that especially the value of $n$-parameter of brass sheets strongly depend on the specimen elongation and stress/strain state. The effect of instantaneous (differential) $n_{t}$-value and $r_{t}$-value on the forming limit curve was computed theoretically.

\section{INTRODUCTION}

There is still great interest in the workability prediction of a material during sheet metal forming. This type of processing involves complex sequences of stress and strain states, and the material workability cannot be evaluated through simple procedures such as simple tension testing [1]. Some materials form better than others. Moreover, a material that has the best formability for one stamping may behave very poorly in a stamping of another configuration. For these reasons, extensive test programs are often carried out in an attempt to correlate material formability with value of some mechanical properties. The formability of sheet metal has frequently been expressed by the value of:

\section{strain hardening exponent $n$, and plastic anisotropy ratio $r$.}

The stress-strain and hardening behaviour of a material is very important in deter- 
mining its resistance to plastic instability. In sheet forming operation biaxial as well as uniaxial stress state exists. Thus, one must known and understands material hardening behavior as a function of stress state $[2,3,4,5,6,7,8]$. Additionally the value of the $n$ and $r$ parameters depend on the grain size of the material [9] and changes as plastic deformation accumulates.

Since experimental determination of the forming limit diagram of a sheet metal is very timeand material-consuming, the knowledge of the above mentioned relations could be very useful in the theoretical calculations of the limit strains of a sheet under different strain state. We might to expect that calculations of the forming limit diagram using instantaneous (elongation dependent, instantaneous) value of the normal anisotropy ratio $r_{t}$ and strain hardening exponent $n_{t}$ enable to achieve better correlation between calculated and experimental results.

Experimental studies of formability of various materials have, however, revealed basic differences in behavior, such as the "brass-type" and the "steeltype" [10], exhibiting respectively, zero and positive dependencies on forming limit upon the strain ratio. Such results cannot be reconciled without proper attention to the details of strain hardening behaviors of these materials, particularly as functions of strain and strain ratio.

Modern universal testing machines with appropriate measuring systems for length-width variations allow the usual characteristic values to be ascertained together with $r$ and $n$ values, both rationally and with a high accuracy.

\section{Material and Mechanical Testing}

The tests were carried out on the $1,0 \mathrm{~mm}$ thick 80-20 and 0,5 mm thick 63-37 brass sheets in annealed state. The tensile specimens of $50 \mathrm{~mm}$ gauge length and $12,5 \mathrm{~mm}$ width, were prepared from strips cut at $0^{\circ}, 45^{\circ}$ and $90^{\circ}$ according to the rolling direction of the sheet. The experiments were carried out using a special device which recorded simultaneously the tensile load, the current length and width of specimen, using a microcomputer. In order to determine the flow properties of a material in biaxial stretching, the bulge test was carried out, using hydraulic bulge apparatus with a circular die aperture of $100 \mathrm{~mm}$ diameter. The bulging pressure and the curvature of the pole were measured and recorded continuously up to specimen failure.

\section{Plastic Anisotropy Ration}

Normal anisotropy value represents the ratio of the natural width deformation in relation to the thickness deformation of a strip specimen elongated by uniaxial tensile stress:

$r=\frac{\varepsilon_{w}}{\varepsilon_{t}}$

The $r$-value at a given elongation, usually $15 \mathrm{pct}$ $(\varepsilon=0,14)$ has been used for many years as a quality control indicator of drawability. More recently, there has been interest in the effect of strain on the plastic ratio, while acknowledging that the changes in the crystallographic texture occurred with increasing strain. For plasticity studies, the basic definition of $r$-value has been replaced with the instantaneous $r_{t}$-value, which is defined as:

$r_{t}=\frac{d \varepsilon_{w}}{d \varepsilon_{t}}$
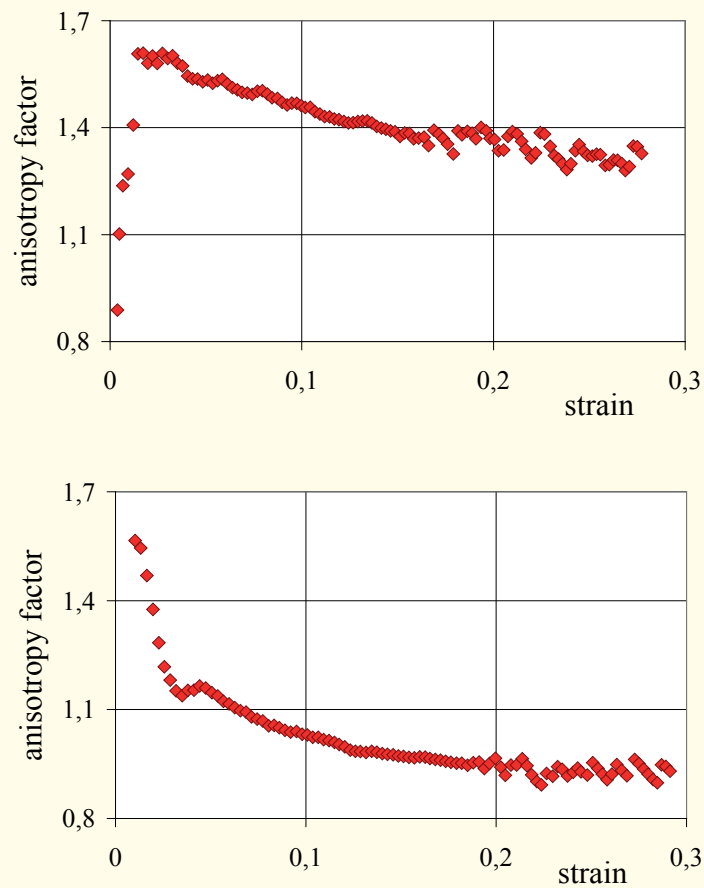

Fig. 1 Variation of $r_{t}$ - value with strain for the 63-37 brass sheet specimens cut at $0^{\circ}$ (upper) and $45^{\circ}$ (lower) according to rolling direction 
According to the latest experimental results $[2,9,11,12]$ no systematic increase or decrease of $r_{t^{-}}$ value with strain was observed, in contrast to previous reports in the literature. The test results for different materials and for different specimen orientation (Fig. 1) have shown that in the case of the 80-20 and 63-37 brass sheets no clear correlation between plastic anisotropy ratio and specimen elongation exists. And because of that the $r$-value of brass sheet was determined using [13] method (Fig. 2), and it could be treated as a reasonable representation of anisotropic behaviour over a wide range of elongation.

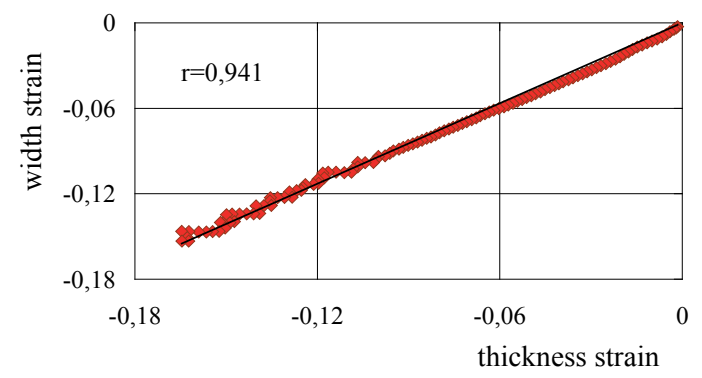

Fig. 2 Plastic anisotropy ratio of the 63-37 brass sheets determined by Welch et al. method

\section{Strian Hardening Exponent}

For many years strain hardening laws such as those from Ludwig, Hollomon, Voce, Swift and Krupkowski has been used to describe the plastic behaviour of polycrystalline metals and alloys. The Hollomon law in the form of:

$\sigma=K \varepsilon^{n}$

has been used the most frequently. The parameters involved in this laws, particularly $n$-value has been, and continue to be, correlated to changes in the microstructure of a material and in some way represents processes which occur during deformation. They have also been used extensively to characterize the formability of sheet material.

The value of strain hardening exponent $n$ is usually determined from the double logarithmic plot of the true stress and true strain by linear regression. When copper and brass sheets are concerned the logarithmic strain-stress relation is not a straight line - and that was observed in the case of 80-20 brass sheet under both the uniaxial and biaxial straining. The $n$-value is strain dependent what resulted from the changes in the crystallographic texture $[13,14]$. Because of this the mean $n$-value (which describe the strain hardening of the whole strain range) and instantaneous $n_{t}$ - value were determined on the base of the results of uniaxial and biaxial testing.

Equation (3) assumes a constant $n$-value and the average $n$-value is measured at a given strain range or can be determine for the whole range of straining from double logarithmic stress-strain data by a least squares approach. To examine the true strain hardening behaviors the instantaneous $n_{t}$ - value should be determined. taking the derivative from equation (3) yields:

$\frac{d \sigma}{d \varepsilon}=K n \varepsilon^{n-1}=\frac{\sigma}{\varepsilon} n$

which results in:

$$
n_{t}=\frac{d \sigma}{d \varepsilon} \frac{\varepsilon}{\sigma}
$$
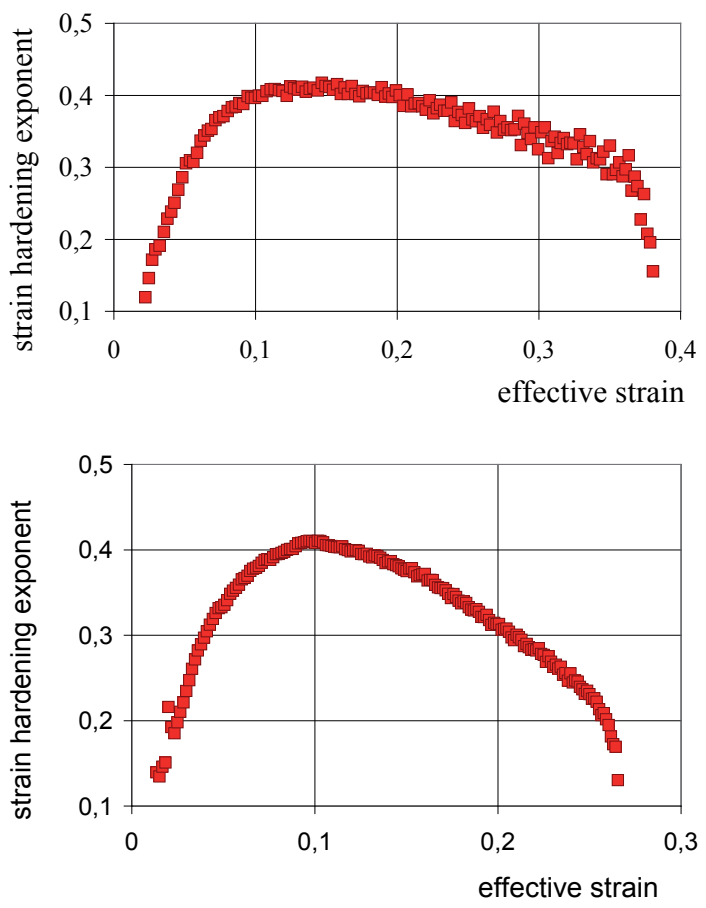

Fig. 3 Variation of $n_{t}$-value with strain for the $80-20$ brass sheet, under uniaxial (upper) and equibiaxial testing (lower) 
The results presented in Fig. 3 show clearly that there is no unique constant $n$-value which may characterize hardening process in both uniaxial and biaxial deformation of brass sheets.

The intensity of strain hardening depends on the true strain [15]. In the case of materials tested instantaneous $n_{t}$ - value varies continuously with strain-increases rapidly at small strains and at higher strains falls again somewhat less rapidly. It was established [16] that at large strains (above 0,10) stress is controlled by the cell size. This observation suggested that there is a change in the accommodation process from the grain level at low strains to the cell level at large strains - what resulted in a change in the strain hardening process.

Variation of the $n_{t}$ - value is strain and strain state dependent (Fig. 3). In the case of uniaxial testing of the 80-20 brass sheet the nt-value riches its maximum at $\varepsilon=0,15$, while in the case of biaxial stretching at $\varepsilon=0,10$. These points could be treated as the beginning of quasistatical range of deformation process. The strain value of $\varepsilon=0,36$ and $\varepsilon=0,26$, for uniaxial and biaxial testing respectively, are the limit strains.

\section{Forming Limit Diagram}

The forming limit diagram (FLD) is today a generally accepted measure of sheet metal formability. It is extensively used in both scientific research and industrial practice. The FLD defines the extent to which a sheet can be strained before a sharp neck and final failure occur. The diagram presents the forming limit for a range of deformation modes ranging from deep drawing (negative minor strains, uniaxial tension) to stretch forming (positive minor strains, biaxial tension). The FLDs of the brass sheets were calculated basing on the M-K theory [17] - a sheet element was divided into two parts, region A with no material defects and region $\mathrm{B}$, softened due to a presence of surface dimples and internal defects. The solution to the M-K problem was achieved in straight-forward incremental numerical procedure of calculations. In our calculations of the FLD we have used no fitting parameters to describe the inhomogeneity of a material, but we have based on experimentally obtained relations [18] which describe the material softening and strain localization processes.

When the influence of plastic anisotropy ratio on the FLD brass sheets is concerned, the following calcula-

\section{tions were performed:}

- calculations of the FLD using the value of mean normal anisotropy ratio $r$,

calculations of the FLD using two different type of instantaneous $r t$-value and elongation relation - the increasing and decreasing function.

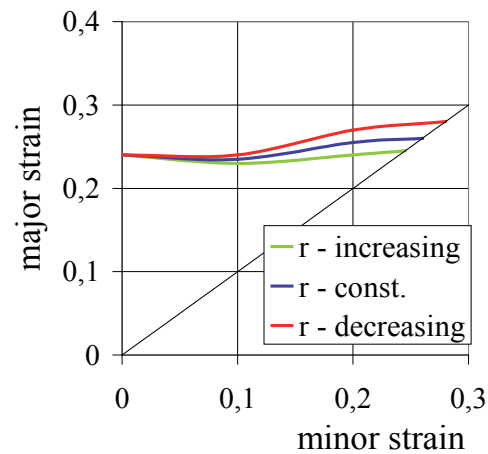

Fig. 4 Effect of instantaneous anisotropy ratio changes (increasing and decreasing function of elongation) on the forming limit curve position

The FLD calculations using instantaneous $r_{t}$ - value as a two types of function of elongation (Fig. 4) has shown that in the $\varepsilon_{2}>0$ region increasing function of $r_{t}$-value resulted in decreasing of limit strains while when using the decreasing function the limit strains increase. This effect was the most visible for the equibiaxial stretching.

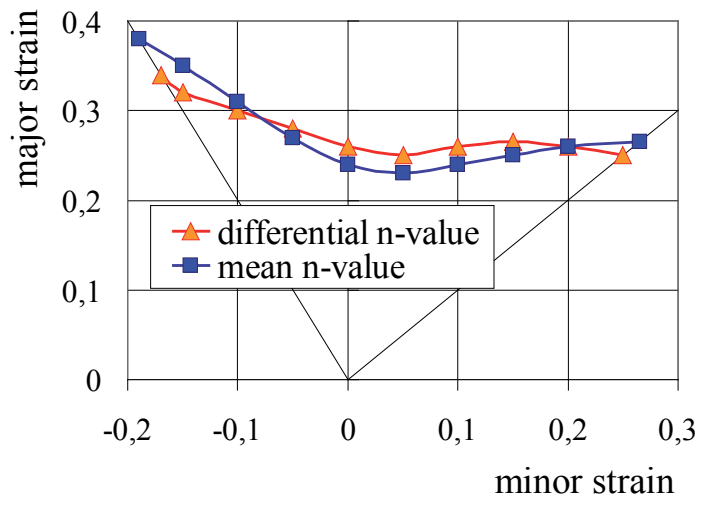

Fig. 5 Effect of instantaneous anisotropy ratio changes (increasing and decreasing function of elongation) on the forming limit curve position

As it was mentioned above the second important parameter affected the FLD is the strain hardening 
exponent. The knowledge of the differences in the hardening process during deformation seemed to be very useful in FLD calculations. Theoretically determined FLD presented in Fig. 5 demonstrate that forming limit curves calculated using both mean n-value and instantaneous $n_{t}$ - value are different in the shape. The FLD calculated using instantaneous strain hardening exponent as a function of effective strain Fig. 3 is more flat than that of the FLD calculated using mean $n$-value - however the position of these two FLD is very close.

\section{Conclusion}

The two most important material parameters - plastic anisotropy ratio (r) and especially strain hardening exponent (n) of brass sheets strongly depend on the strain state. Both the $n$ and $r$ parameters are strain dependent, so in some cases instantaneous nt and $r_{t}$ value more precisely represent a material properties. These remarks should be taken into account in predicting sheet metal formability (forming limit diagram) as well as in numerical modeling of sheet metal forming processes.

\section{References}

[1] Pereira I.M., Rubim G., Acselrad O., Cetlin P.R., Comparison of the experimental and the numerically predicted mechanical damage in the sheet forming of steel, Journal of Materials Processing Technology, vol. 203, 2008, p. 13-18

[2] Doucet A.B., Wagoner R.H., Transient tensile behavior of Intersitial-Free steel and 70/30 brass following plane-strain deformation. Metallurgical Transactions, vol. 20A, 1989, p.14831493

[3] Vial C., Yield locus of 70-30 brass sheets, International Journal of Mechanical Science, vol. 30, No. 2, 1988, p. 137-145

[4] Shi M.F., Strain hardening and forming limits of automotive steels, SAE Transactions, vol.104, 1995, p. 571-577

[5] Mahmudi R., Stress-state dependence of workhardening behavior in aluminium alloy sheet, Journal of Materials Processing Technology, vol. 72, 1997, p. 302-307

[6] An Y.G., Vegter H., Elliot L., A novel and simple method for the measurement of plane strain work hardening, Journal of Materials Processing Technology, vol. 155-156, 2004, p. 16161622
[7] Slota J., Spišak E., Determination of flow stress by the hydraulic bulge test, Metalurgija, vol. 47, no. 1, 2008, p. 13-17

[8] Dournaux J.L., Bouvier S., Aouafi A., Vacher P., Full-field measurement technique and its application to the analysis of materials behaviour under plane strain, Materials Science and Engineering A, vol. A 500, 2009, p. 47-62

[9] Stachowicz F., On the mechanical and geometric inhomogeneity and formability of aluminium and aluminium alloy sheets. Archives of Metallurgy, vol. 41, no. 1, 1996, p. 61-75

[10] Ghosh A.K. Plastic flow properties in relation to localized necking in sheets. In D.P. Koistinen \& N-M. Wang (ed.), Mechanics of sheet metal forming, Plenum Press. New York 1978, p. 287312

[11] Rao K.P., Mohan E.V.R., A unified test for evaluating material parameters for use in the modelling of sheet metal forming, Journal of Materials Processing Technology, vol. 113, 2001, p. 725-731

[12] Chamanfar A., Mahmudi R., Compensation of elastic strains in the determination of plastic strain ratio $(R)$ in sheet metals, Materials Science and Engineering A, vol. A 397, 2005

[13] Welch P.I., Ratke L., Bunge H-J., Consideration of anisotropy parameters in polycrystalline metals, Zeitschrift für Metallkunde, vol. 74, 1983, p. 233-237

[14] Hill R., J.W. Hutchinson, Instantaneous hardening in sheet metal under biaxial loading: A theoretical framework, Journal of Applied Mechanics, vol. 59, 1992, p. S1-S9

[15] Ding Hao, Ding Hua, Song D., Tang Z., Yang P., Strain hardening behavior of a TRIP/TWIP steel with 18,8\% Mn, Materials Science and Engineering A, vol. A 528, 2011, p. 868-873

[16] Gracio J.J., Fernandez J.V., Schmitt J.H., Effect of grain size on substructural evolution and plastic behavior of copper. Materials Science and Engineering A, vol. A 118, 1989, p. 97-105

[17] Marciniak Z., Kuczyński K., Limit strain in the process of stretch forming of sheet metals, International Journal of Mechanical Science, vol. 9, No, 1967, p. 609-624

[18] Stachowicz F., Effect of material inhomogeneity on forming limits of 85-15 brass sheets, Archives of Metallurgy, vol. 36, no. 2, 1991, p. 223-242 


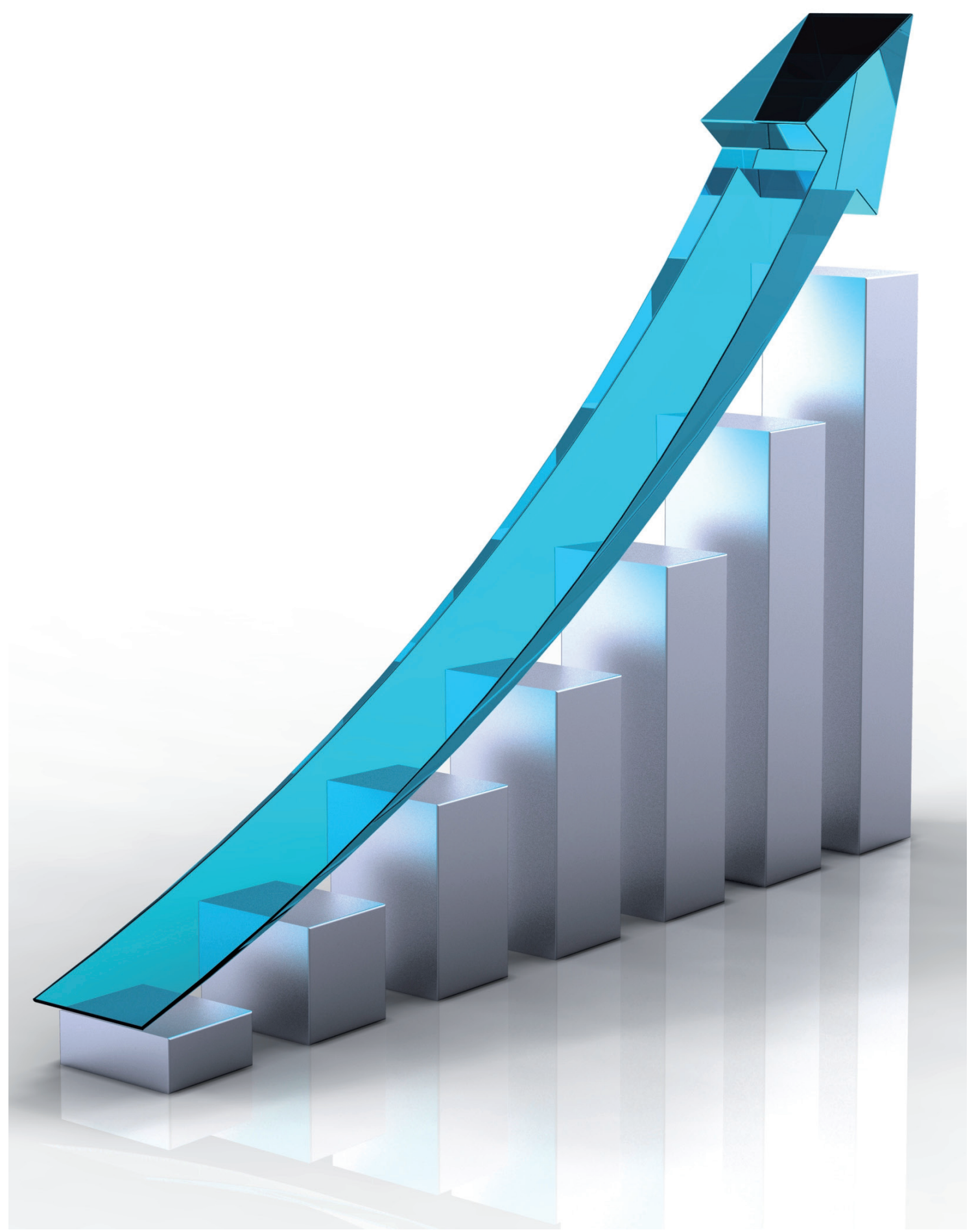

